\title{
ECOTORISMO OS ATRATIVOS NATURAIS EM BUJARU/PARÁ
}

Gelson Carneiro da SILVA ${ }^{1}$

Faculdade de Turismo do Instituto de

Ciências Sociais Aplicadas UFPA gelson@ufpa.br

Carlos Américo Lima VASCONCELOS ${ }^{2}$

Escola de AplicaçãoUFPA cavasco@ufpa.br

Haydeé Borges FONSECA ${ }^{3}$ Faculdade de AdministraçãoUFPA

hay@ufpa.br

Resumo: o ecoturismo é um segmento do turismo que vem crescendo cada vez mais e tem contribuído para o desenvolvimento econômico e social da localidade. Isto porque se mostra como um potencial para a melhoria de vida das comunidades envolvidas, além da proteção, da conservação e preservação do meio ambiente. Como alternativa de lazer, o ecoturismo, baseado no tripé do desenvolvimento sustentável (preservação e conservação do meio ambiente, desenvolvimento da localidade e envolvimento e crescimento econômico da comunidade), não se limita apenas ao uso sustentável natural de agora, e sim busca viabilizar a minimização das consequências do fluxo de turistas, valendo-se de um controle da capacidade de

\footnotetext{
${ }^{1}$ Turismólogo pela Universidade Federal do Pará - UFPA. Especialista em Ecoturismo pelo Núcleo de Meio Ambiente-NUMA/UFPA. Atualmente (2009), desempenha atividades de caráter técnico-administrativas na Faculdade de Turismo do Instituto de Ciências Sociais Aplicadas da Universidade Federal do Pará - FACTUR/ICSA/UFPA. gelson@ufpa.br

${ }^{2}$ Geografo pela Universidade Federal do Pará - UFPA, Especialista em Geografia Econômica pela Fundação Educacional Severino Sombra - FUSVE, Brasil e Especialista em Ecoturismo pela Universidade Federal do Pará - NUMA/UFPA. Atualmente (2009), é Professor de Geografia do Núcleo Pedagógico Integrado da Universidade Federal do Pará. cavasco@ufpa.br

${ }^{3}$ Bacharel em Serviço Social pela Universidade Federal do Pará - UFPA, Especialista em Gestão do Planejamento em Desenvolvimento Regional - UFPA. Atualmente (2009), realiza Curso de Mestrado em Planejamento do Desenvolvimento no NAEA/ UFPA. Desempenha atividades de caráter técnico-administrativas na Faculdade de Administração da UFPA. hay@ufpa.br.
} 
suporte da localidade, servindo de base à fiscalização da degradação ambiental que o fluxo de turistas pode proporcionar ao ambiente natural visitado. Neste artigo, apresentamos como essa modalidade vem sendo desenvolvida no Município de Bujaru e suas adjacências.

Palavras-chave: Ecoturismo. Desenvolvimento Local. Turismo Sustentável.

Abstract: Ecotourism is a segment of tourism that is growing increasingly and has contributed to the economic and social development of the town. This is because it shows how a potential for improving the lives of the communities involved, in addition to the protection, conservation and environmental preservation. Alternatively recreation, ecotourism, based on the triad of sustainable development (preservation and conservation of the environment, development and involvement of village community and economic growth) is not limited to the sustainable use of natural now, but make the search minimization the consequences of the flow of tourists, drawing up of a control the ability to support the town, serving as the basis for monitoring the environmental degradation that the flow of tourists can provide the environment visited. In this article we present how this method has been developed in the municipality of Bujaru and their surroundings.

keywords: Ecotouris. Local Development. Sustainable Tourism.

\section{Introdução}

O turismo tem excelentes perspectivas no século XXI e ocupa hoje papel relevante na economia mundial, sendo o terceiro, entre os maiores produtos geradores de riqueza. O turismo tem fomentado, como um dos serviços mais promissores na geração de trabalho e renda, mas também tem sido denunciado por sua capacidade de devastação e degradação da natureza ao transformar regiões, quando praticado sob um modelo que não incorpora a sociedade local. Segundo Fennell (2002), o turismo tem duas vertentes principais: o turismo alternativo e o turismo de massa. No primeiro caso, o turismo é conhecido como agente que fornece o ímpeto para o desenvolvimento apropriado de longo prazo. No segundo, gera perturbações ecológicas e sociológicas em regiões [que são] devastadas por práticas de turismo de massa, que valoriza mais o artificial, o consumismo, o luxo, marginalizando a cultura local e a população do entorno. Como 
exemplo desse modelo turístico, desvinculados do entorno, pode-se citar os resorts.

No turismo alternativo, as políticas do setor não se concentram apenas nas necessidades econômicas e técnicas, mas enfatizam a demanda por um ambiente não degradado e valorizam as necessidades da população local. Neste modelo, surge o ecoturismo, como novo segmento do turismo, que segundo Ceballos-Lascurain (1995), é uma modalidade que não tráz grandes impactos ao meio ambiente, à biodiversidade e à cultura local, tendo em vista que praticantes buscam contato com áreas ainda pouco exploradas em termos sociais, ou seja, contatos com paisagens, plantas e animais silvestres sem agredi-los.

Assim, para que esta atividade turística possa ser desenvolvida são necessárias diretrizes capazes de proporcionar uma política voltada à valorização da natureza, portanto, do ecoturismo, compreendido como conservação do patrimônio natural e cultural, sob uma perspectiva de conscientização ambientalista, que trata da interpretação do ambiente como bem-estar das populações. E ainda, de acordo com Lascurain (1995), o ecoturismo é vital à medida que possibilita o desenvolvimento sustentável e uma abordagem multidisciplinar, sob um planejamento primoroso em relação ao meio físico e gerencial.

Esta perspectiva da atividade turística tem contribuído efetivamente para o desenvolvimento local, ao dinamizar práticas socioeconômicas e culturais das populações envolvidas, sob um novo paradigma. No contexto global, a manutenção das identidades culturais tem repercutido, muitas vezes, em fortes atrativos de lazer e de conhecimento para o público visitante. Outro aspecto relevante desta modalidade, diz respeito ao desenvolvimento sustentável, que tem sua base no respeito e cuidado com a comunidade, conservação do meio ambiente natural, bem como de hábitos e costumes tradicionais, conservando a vitalidade e a diversidade dos seres vivos, melhorando a qualidade de vida da comunidade envolvida.

Trata-se, na realidade, de estabelecer certos critérios e regulamentos face aos limites e capacidade de suporte do local, minimizando o esgotamento dos recursos não-renováveis, modificando atitudes e práticas das pessoas ao permitir que as comunidades humanas cuidem de 
seu próprio ambiente e, desta forma, busquem o desenvolvimento sem deteriorar o patrimônio cultural, os recursos naturais e o ambiente. Sob esta definição, pode-se afirmar que o ecoturismo é capaz de gerar processos de gestão ambiental tendo em vista sua competência específica de utilizar e renovar, simultaneamente, os recursos naturais, sem comprometer a capacidade de atender as gerações futuras.

Para entender as práticas de ecoturismo no estado do Pará, mostrase a experiência no Município de Bujaru e suas adjacências, porém, antes de entrar nessa realidade é importante discorrer sobre a compreensão do ecoturismo à medida que se utiliza esta modalidade para mostrar sua importância ao desenvolvimento no Estado.

O ecoturismo, como instrumento de operacionalização das ações e atividades do turismo no Município de Bujaru/PA, particularmente em sua zona periurbana, oferece aos visitantes um contato direto com a natureza. Os igarapés existentes na localidade são propícios ao lazer, enquanto as ruínas do engenho Bom Intento possibilitam revisitar um pouco da história paraense. $\mathrm{O}$ modo de vida das comunidades que habitam esse espaço e suas diversas atividades de subsistência, tais como a apicultura, a produção de farinha d'água, passeios de canoa e caminhos em trilhas podem também tornarem-se atrativos interessantes. Neste sentido, mostra-se como o ecoturismo pode se constituir como uma estratégia de sustentabilidade sob a perspectiva de desenvolvimento local.

\section{Ecoturismo, sustentabilidade e preservação ambiental: um novo paradigma do turismo}

O excesso de pessoas degrada e altera o apelo estético do produto turístico e diminui o interesse dos visitantes pelos atrativos. Se um novo destino começar a ser intensamente divulgado e ocasionar um aumento significativo do fluxo de visitação, sem que tenham sido tomadas providências para impedir sua degradação, certamente esse lugar em bem pouco tempo não servirá mais à prática ecoturística.

A utilização de terras para Unidades de Conservação, assim como a escolha de locais para a instalação de grandes complexos hoteleiros frequentemente é repleta de riscos ambientais e injustiças sociais face 
aos processos de remanejamento das populações locais, muitas vezes de forma ilegal ou mesmo compulsório. Hoje, com o mundo cada vez mais consciente dos direitos e responsabilidades dos cidadãos, a conservação torna-se uma exigência, ainda mais quando o problema do aquecimento global decorre das formas de exploração da natureza com objetivos eminentemente empresariais, para obtenção do lucro, o que tem levado ao desrespeito às populações locais. Conforme estabelece Lindberg (1995), a atividade turística além de melhorar a economia regional é capaz, também, de alterar a cultura de um povo, sendo este um motivo suficiente para o descontentamento de muitas pessoas, que passam a direcionarem-se contrárias à implantação de seu desenvolvimento. Sob esta perspectiva, o turismo que nega os direitos e preocupações das comunidades são autodestrutivos, senão ilegais.

Costa (2005, p. 73), pensando na contramão deste modelo, afirma que o "o ecoturismo deve contribuir para a conservação das áreas naturais e para o desenvolvimento sustentável das áreas adjacentes e das comunidades que as habitam".

$\mathrm{Na}$ contemporaneidade, a busca por ações e estratégias de desenvolvimento sustentável sob vários aspectos das cidades e seu entorno revela uma crítica às atividades do turismo de massa ou mesmo do chamado turismo voltado a classe "A", pois se volta à geração de trabalho, emprego e renda. Isto tem permitido que as comunidades tornem-se um espaço essencial para os habitantes das grandes metrópoles, mas também das grandes e médias cidades, à medida que a sociedade contemporânea, devido à aceleração dos processos gestados na vida urbana precisa de lazer a fim de revigorar suas forças e melhor condição de saúde.

O contato com o campo é outro elemento importante para as populações dos grandes centros urbanos, devido à descontração e consequentemente sensação de prazer. Também se constitui em um novo conhecimento à medida que essas populações se educam no contato direto com outras realidades e, desta forma, apreende/assimila novas maneiras de relacionar-se com os outros; conhecimento proporcionado pelas informações adquiridas, além de possibilitar novos padrões de sociabilidade. 
Hoje, se tem buscado associar às intervenções urbanísticas a implantação de áreas verdes, como parques ambientais, bosques, lagos artificiais, jardinagem e outros espaços capazes de possibilitar um tipo de "encontro" entre o homem e a natureza, potencializando o exercício prático de contato com nossas origens, isto é, o homem-natureza e, neste sentido, a preservação e conservação do meio ambiente revela-se como um oásis. A contemplação de belezas naturais para a atividade ecoturística é outro ponto tratado por Costa (Idem), pois é através dela que se pode gratificar várias experiências no meio ambiente natural.

O Ministério do Turismo (1995) evidencia a atividade do ecoturismo, no momento em que se mostra como um potencial diferenciado ao organizar suas ações de modo a promover o patrimônio natural e cultural, garantindo o incentivo à conservação, além de desenvolver uma consciência ambientalista, necessária à preservação do ambiente e bem-estar social.

Para Dias (2003, p. 94), o turismo na relação direita com a natureza tem forte vínculo com a biodiversidade pela atratividade que "exerce os ricos e variados ambientes naturais". No entanto, o autor chama a atenção para o fato de saber se esta atividade uma vez de uso intensivo em localidades biodiversas, pode afetar profundamente ou não o panorama natural, além dos impactos negativos, causando, em última instância, a perda da própria atividade turística, haja vista que a mesma é impulsionada pelas condições naturais.

Neste sentido, a Região Amazônica e o Pará, em especial, mostramse com um grande potencial para as atividades do ecoturismo. Desde que mantido o manejo adequado. Na mesma linha de pensamento Costa (2005, p.15), ressalta que a $\mathrm{OMT}^{4}$, visando estimular os governantes, empresários, comunidades locais e os visitantes para impulsionarem a atividade ecoturística, estabeleceu o ano de 2002 como sendo o Ano Internacional do Ecoturismo, a fim de impulsionar o desenvolvimento sustentável na atividade do turismo.

${ }^{4}$ A Organização Mundial de Turismo (OMT) é uma agência especializada das Nações

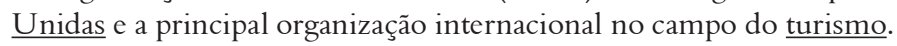




\section{Os atrativos ecoturísticos do Município de Bujaru e suas adjacências}

O Município de Bujaru ${ }^{5}$ está situado a, aproximadamente, 83 (oitenta e três) quilômetros da cidade de Belém, capital do Estado do Pará, com cerca de $01 \mathrm{~h} 30 \mathrm{~min}$ de viagem pela rodovia PA-140, conforme observa-se no Mapa ${ }^{6}$ abaixo, e tem as seguintes coordenadas: geográficas 01 $58^{\prime} 10^{\prime \prime}$ de latitude sul e 47059'00" de longitude a Oeste de Greenwich, conforme pode ser observado no mapa a seguir.

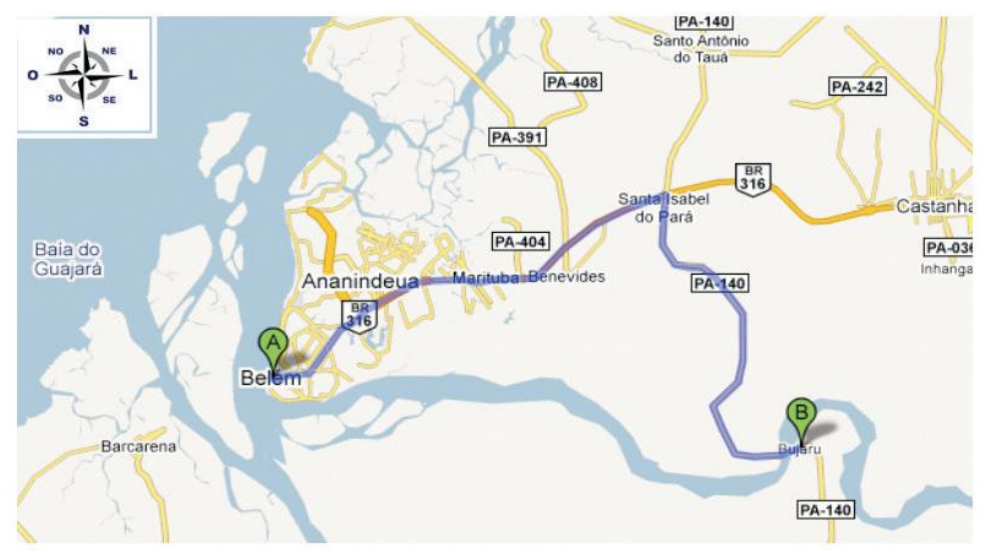

MAPA: Localização do município de Bujaru/PA, partindo da cidade de Belém (Capital do Estado do Pará).

A origem do nome Bujaru é derivada do vocábulo Tupi, que significa "Boca de Cobra", remonta do ano de 1758, quando era distrito do município denominado de São Domingos da Boa Vista ${ }^{7}$. A denominação

\footnotetext{
${ }^{5}$ Bujaru, em 1838, perdeu a qualidade de distrito e passou a figurar como zona de distrito - sede do município de São Domingos do Capim e, finalmente, em 1943 foi constituída como município autônomo, pelo Decreto-Lei no 4.505 de 30/12/1943 homologado pela autoridade do interventor federal, tenente-coronel Joaquim Cardoso de Magalhães Barata, A partir da constituição federal de 1988 e segundo a Lei 5442 de 10/05/1988, foi desmembrado para constituir o município de Concórdia do Pará. Hoje, (2008) Bujaru é composto, também, pelo distrito de Guajará-Açu.

${ }^{6}$ Fonte: http://maps.google.com.br/maps?hl=pt-BR\&tab=wl\&q= bujaru\%20pa

${ }^{7}$ Atualmente denominado São Domingos do Capim.
} 
"Bujaru" provem do rio que atravessa o município e que vários igarapés 8 . Esses cursos d'água de profundidade pequena e média dificilmente atingem três metros entre a lâmina d'água e o talvegue ${ }^{9}$, tornando uma das maiores riquezas da localidade, devido sua importância para o ecoturismo, também se observa que a localidade apresenta tratos recobertos por floresta, onde seu subtipo é a Floresta Densa de baixos platôs e florestas Secundárias ou capoeiras em vários estágios de regeneração e grande atividade de desmatamento.

O Município de Bujaru é pródigo desses atrativos, mas seu uso depreciativo pela população local pode destruir esse meio ambiente à medida que falta uma percepção imediata dessa grandeza natural e da própria atividade ambiental. Esses atrativos são explorados pela população numa visão massiva e consumista. Ainda não há uma mentalidade em relação ao desenvolvimento sustentável, o qual move o ecoturismo, e cuja prática é a de conservação. A origem do município deve-se a ocupação de famílias nordestinas, que ali chegaram devido à crise da economia da borracha e passaram a desenvolver atividades agrícolas e a criação de pequenos animais, atraídas pela potencialidade das terras.

No aspecto cultural, nota-se que a população do município de Bujaru tem sua devoção, maior, voltada a Nossa Senhora de Sant'Ana, tendo suas festividades realizadas no dia 20 do mês de julho, duas outras atividades festivas são as comemorações ocorridas para entre os dias $16 \mathrm{e}$ 31 de agosto para os santos de São Joaquim e São Raimundo.

A natureza é um dos principais atrativos turísticos do município de Bujaru. Cercado com uma vegetação exuberante, com localidades propícias à implantação da atividade ecoturística. A localidade chamada de Vila Ponta de Terra, situada a $15 \mathrm{~km}$ (quinze quilômetros) depois do município de Bujaru, na rodovia PA-140, entrando à sua margem direita distante mais $5 \mathrm{~km}$ (cinco quilômetros), oferece grandes possibilidades de aproveitamento de caminhos já abertos, às atividades de trilhas interpretativas findando o passeio à margem do Igarapé Ponta

${ }^{8}$ Igarapé nome derivado da língua indígena e significa "caminhos de canoa", mas para o restante do Brasil são chamados de riachos e arroios.

${ }^{9}$ Linha sinuosa no fundo de um vale pela qual correm as águas. São excelentes produtos atrativos para ecoturistas. 
de Terra, onde o visitante poderá desfrutar de um contato direto com a natureza e maravilhar-se com as riquezas que o meio ambiente pode proporcionar-lhe, tais como igarapés e trilhas ecológicas existentes na zona rural. Um outro forte atrativo aos visitantes é o Forno Comunitário, onde o visitante poderá aprender o manuseio da fabricação de farinha de mandioca, farinha de tapioca e cuscuz, sendo que um desses fornos comunitários está presente às proximidades da Vila Ponta de Terra.

Para melhor aproveitar às belezas existentes em Bujaru, o visitante poderá maravilhar-se com as Ruínas do Engenho Bom Intento, onde se poderá desfrutar de caminhadas em trilhas interpretativas e entrar em contato direto em uma das ruínas que servem de referencial histórico da cultura do povo paraense.

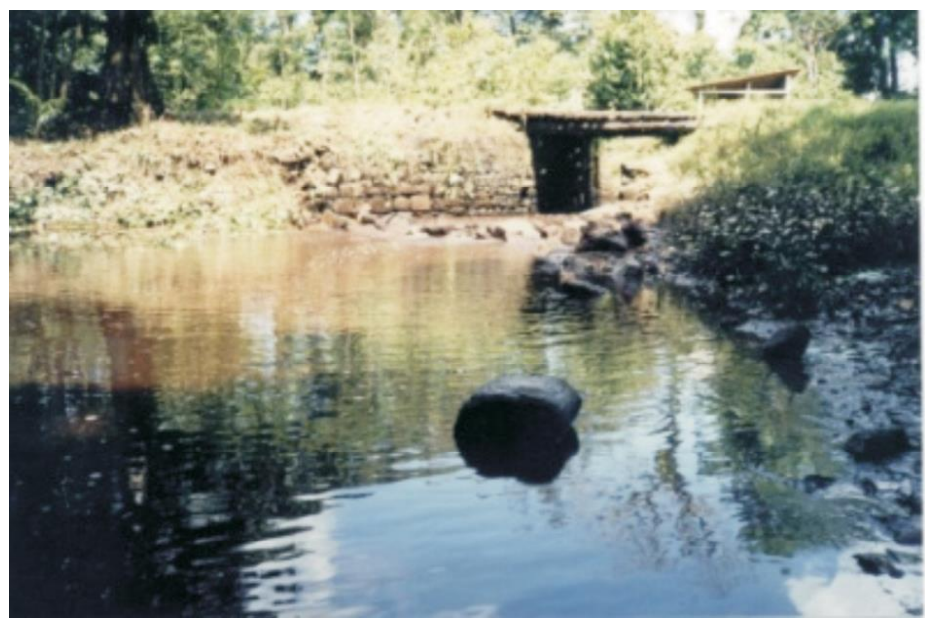

Foto 1 - Igarapé localizado às proximidades das ruinas do Engenho Bom Intento

A localidade denominada de Balneário Cajuíra fica na zona urbana seguindo pela PA-140, [situada] a 20 (vinte) $\mathrm{km}$ ao lado direito, entrando mais $5 \mathrm{~km}$, em estrada de terra batida, dispõe de grandes possibilidades e atrativos para as atividades ecoturística. Observa-se, também, alguns pontos diferenciadores dos atrativos ecoturísticos, tais como o Balneário Cajuíra cujo local serve para receber visitantes aos finais de semanas e feriados. Durante os dias de semana a comunidade utiliza-o para lavagem de utensílios domésticos, vestuários e banho. 
Outra opção de contato com a natureza é a Fazenda Santa Fé do Cajuíra, localizada às proximidades do Balneário do Cajuíra, a $20 \mathrm{~km}$ (vinte quilômetros) da zona urbana do município de Bujaru/PA. Além da produção em trabalhos agrícolas, a Fazenda Santa Fé do Cajuíra dispõe, inclusive, de Atividades de produção de pimenta do reino. Essa atividade funciona para fornecer pimenta-do-reino aos comerciantes do setor urbano do município de Bujaju e também abastecer Belém (Capital do Estado do Pará). Além disso, a fazenda dispõe da plantação de mamoeiros, bananeiras e coqueiros, sendo que a atividade de plantio começou com iniciativa do proprietário da fazenda e visa fins comerciais à zona urbana e à capital, Belém/PA.

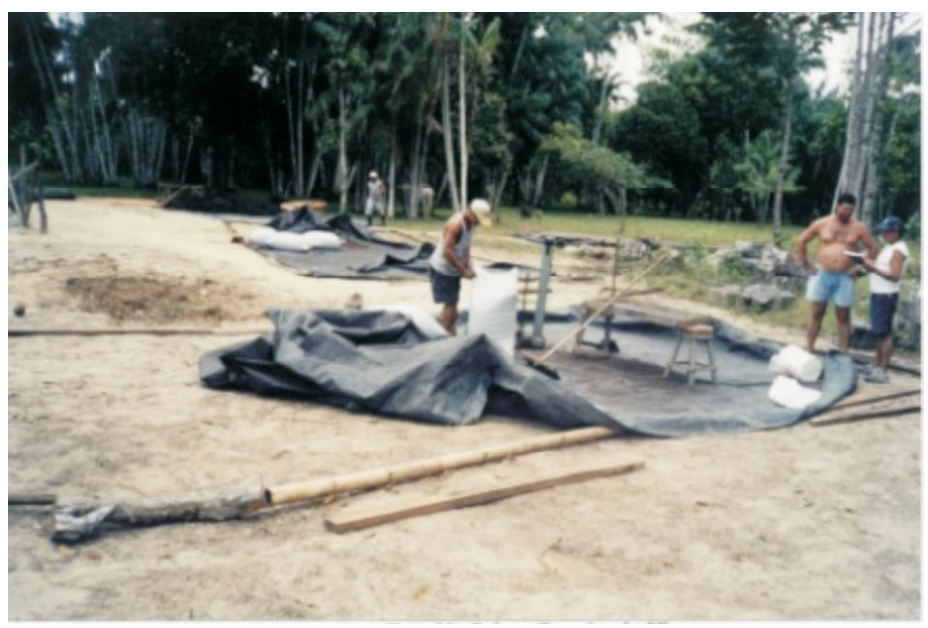

Foto 2: Produção de Pimenta do Reino, na fazenda Santa Fé do Cajuíra - Zona rural

Uma forte opção de lazer e entretenimento é o Igarapé do Sabonete, localizado a $9 \mathrm{~km}$ (nove quilômetros) da zona urbana do município de Bujaru, possuindo uma excelente estrutura para os aproveitamentos dos caminhos já abertos nas atividades de trilhas interpretativas, lazer e entretenimento às atividades ecoturísticas.

O Balneário do Castanheiro é uma outra opção, aguda, para empreendimentos ecoturísticos, oferecendo aos visitantes uma boa opção para um banho agradável, passeio em trilhas interpretativas, lazer e é lá onde encontram-se as "Pedras Patateua", que são pedras que chegam a 
alcançar $2 \mathrm{~m}$ (dois metros) de altura. No Balneário do Castanheiro podese observar que está em adiantado processo de assoreamento, com pouca mata ciliar, demonstrando que esse atrativo tem tempo de vida curto se não for tecnicamente recuperado.

O ecoturismo é uma atividade muito exigente, pois requer uma postura educacional apropriada tanto dos visitantes quanto dos moradores do local visitado. Além de ser uma prática recente no Estado do Pará, a baixa escolaridade é uma variável plausível para se entender essa atividade tão complexa.

Há necessidade premente que o poder público incentive a inclusão e a prática da Educação Ambiental desde já, pois os resultados educacionais não acontecem de imediato, mas sim a médio e longo prazos.

A foto $\mathrm{n}^{\mathrm{o}} 3$ salienta um dos símbolos da flora Amazônica que é a castanheira (Bertollethia Excelsa), como seu nome científico enfatiza é uma árvore de grande porte, cujo fruto é um dos mais ricos em nutrientes e teve uma importância econômica na Amazônia, sua beleza e importância não podem ser desprezadas pelo ecoturismo, alicerçado pela educação ambiental.

\section{Conclusão}

Para haver uma relação mais intensa com o lugar é preciso vivenciá-lo. É preciso ter outra relação com o tempo, em que a vivência represente uma relação de troca, de aprendizado e de respeito. Muitas vezes a melhoria da qualidade da percepção requer conhecer melhor as características ambientais locais.

A atividade ecoturística é diferente do turismo convencional porque considera que o meio ambiente não deve ser transformado, a fim de atender às expectativas dos visitantes, que precisem ser preparados para a experiência da visitação.

Outros princípios do ecoturismo chamam a atenção, como a utilização dos recursos naturais e culturais de forma sustentável, oferecer produtos de elevada qualidade aos visitantes, contribuir para a distribuição justa dos benefícios econômicos gerados e possibilitar o desenvolvimento de empreendimentos criados e gerenciados pelas próprias comunidades. 
Por causa desse perfil diferenciado, o ecoturista tem interesses e necessidades que exigem de quem planeja a observação de alguns critérios relativos às áreas naturais, ao uso de técnicas, ao envolvimento comunitário, as parcerias, a qualidade dos serviços e a capacitação técnica de mão-de-obra local.

O ecoturista aprecia a beleza e visita a locais bem conservados e com alta qualidade ambiental. Por isso, os empreendimentos ecoturísticos devem promover a conservação de áreas naturais, assim como a recuperação de locais degradados.

As técnicas empregadas não devem agredir o meio ambiente, assim como todas as atividades devem ser constantemente avaliadas devido aos impactos negativos. É preciso estabelecer o nível de impacto que cada local de visitação suporta (controle da capacidade de suporte), visando minimizar os prejuízos ao ambiente natural e cultural da região.

O envolvimento das comunidades é fundamental tanto no planejamento, como na execução e avaliação dos empreendimentos, para que as pessoas sintam-se motivadas.

Nenhum empreendimento ecoturístico pode fazer sucesso isoladamente. Havendo outras iniciativas no local, certamente as chances de atrair visitantes aumentam. Por isso, devem-se desenvolver planos integrados com todos os atores sociais da localidade, incluindo o poder público, o empresariado e a comunidade participativa.

É importante, também, contar com guias de turismo e monitores ambientais integrados aos produtos de ecoturismo, para que os visitantes vivenciem melhor os atrativos e os serviços oferecidos, os quais com toda certeza, tendem a voltar ou fazer propaganda da localidade.

Os empreendimentos dependem de programas de capacitação e treinamentos para todos os envolvidos, ou seja, organizações governamentais e não-governamentais, iniciativa privada, comunidade local e público visitante, especialmente enfatizando programas de educação ambiental.

Por tudo isso, somos otimistas à implantação do ecoturismo no município de Bujaru, cujos atrativos naturais e o predomínio da população rural, já são fatores "sine qua non" para incrementar este segmento do turismo em franco crescimento nos quatro cantos do globo. 


\section{REFERÊNCIAS}

ALMEIDA, J. R. et al. Planejamento ambiental. Rio de janeiro: Thex, 1993.

ALMEIDA, S. Planejamento e manejo de trilhas para o ecoturismo. Texto produzido. Belém/Pará, 2003.

BENI, Mário Carlos. Análise Estrutural do Turismo. São Paulo: Editora SENAC, 1998.

BOUDIER, Pierre. O desencantamento do mundo: estruturas econômicas e estruturas temporais. São Paulo: Perspectiva, 1979.

CAVACO, Carminda. Turismo rural e desenvolvimento local. São Paulo: Hucitec, 1996.

COSTA, Patrícia Côrtes. Ecoturismo. São Paulo: Aleph, 2005. (Coleção: ABC do Turismo).

DIAS, Reinaldo. Turismo Sustentável e Meio Ambiente. São Paulo: Atlas, 2003.

FENNEL, David. Ecoturismo: uma introdução. São Paulo: contexto, 2002. (Coleção Turismo).

SILVA, Gelson Carneiro da. Projeto de pesquisa para desenvolver o turismo na Ilha de Cotijuba. Trabalho de Conclusão de Curso. Belém: UFPA, 1999.

MITRAUD, S. Projeto de desenvolvimento de trilhas interpretativas do Parque Nacional Marinho de Fernando de Noronha/PE. Brasília, 1998.

MOTTA, Ronaldo Seroa da. Manual para Valoração Econômica de Recursos Ambientais. 2a Edição. Brasília, 1998.

PORTAL AMAZÔNIA. Amazônia de A a Z. http://portalamazonia. globo.com/pscript/amazoniadeaaz/artigoAZ.php., 2009.

QUARESMA, Helena Doris de Barbosa. O Desencanto da Princesa: pescadores tradicionais e turismo na área de proteção ambiental de 
Algodoal/Maiandeua. Dissertação de Mestrado.Belém: NAEA/PLADES, 2000.

SWARBROOKE, John. O futuro do turismo sustentável. In: Turismo sustentável: turismo cultural, ecoturismo e ética. V. 5. São Paulo: Aleph, 2000.

XIMENES, Tereza; AZEVEDO, Luíza Elayne; RIBEIRO, Adagenor Lobato. Educação ambiental e manejo de recursos naturais: coletânea de monografias nas temáticas escola/meio ambiente. Belém: UFPA/NAEA, 2002. pp. 108-120. 